\title{
(- axtax \\ Retinal and choroidal circulation determined by optical coherence tomography angiography in patient with amyloidosis
}

\author{
Masami Tei, Ichiro Maruko, Eiko Uchimura, Tomohiro lida
}

Ophthalmology, School of Medicine, Tokyo Women's Medical University, Tokyo, Japan

Correspondence to Dr Ichiro Maruko, imaruko@twmu.ac.jp

Accepted 28 January 2019

Check for updates

(c) BMJ Publishing Group Limited 2019. Re-use permitted under CC BY-NC. No commercial re-use. See rights and permissions. Published by BMJ.

To cite: Tei M, Maruko I, Uchimura $\mathrm{E}$, et al. BMJ Case Rep 2019:12:e228479. doi:10.1136/bcr-2018228479

\section{SUMMARY}

A 43-year-old woman who was diagnosed with the cryopyrine-associated periodic syndrome (CAPS) with severe renal failure and heart failure due to amyloid accumulation was examined by swept source optical cohernce tomography (OCT) (SS-OCT; DRI-OCT, Topcon, Tokyo, Japan) and optical coherence tomography angiography (OCTA) (RTVue XR Avanti, Optovue, Fremont, CA). Her best-corrected visual acuity was 20/40 OD and 20/25 OS. A hyporeflective band of about $100 \mu \mathrm{m}$ thickness was seen just inferior to the retinal pigment epithelium in the cross-sectional SS-OCT images, but the deeper choroidal structures were clearly visible. In the OCTA images, the density of the retinal capillaries in the superficial and deep capillary plexus slabs were reduced, and no signals of the choroidal capillary slab was detected after removing the projection artefacts. The accumulation of amyloid can cause a reduction of both the retinal and choroidal capillary circulations although the circulation in the larger vessels are preserved.

\section{BACKGROUND}

The cryopyrine-associated periodic syndrome (CAPS) is a hereditary autoinflammatory syndrome with fever, exanthema, arthritis, aseptic meningitis and optic neuritis. The chronic inflammation causes amyloid deposits in multiple organs including the eye. ${ }^{1-5} \mathrm{~A}$ case report showed amyloidosis is associated with chorioretinopathy and a thicker hyporeflective choriocapillaris band at the area of choriocapillaris in optical coherence tomography (OCT). Some histopathological study reported an occlusion of the choriocapillaris due to amyloid deposits. The current study is the first report about amyloidosis using OCT angiography (optical coherence tomography angiography [OCTA]), which proved the capillary abnormalities in the retina and choroid in a patient with amyloidosis.

\section{CASE PRESENTATION}

The patient was a 43-year-old woman with recurrent uveitis, undergoing haemodialysis for end-stage renal failure and chronic heart failure. She also had a history of arthritis, cold urticaria and recurrent fever since childhood. Her mother had diabetes mellitus and her father had polyarteritis nodosa. Genetic examination revealed a E304K hetero mutation of the NLRP3 gene, and she was diagnosed with CAPS at age of 35 years.
Her uveitis went into remission after she was treated with anakinra (Kineret). She had cataract surgery on the right eye at age of 38 years and in the left eye at 43 years.

Although her visual acuity was 20/40 oculus dexter (OD) and 20/25 oculus sinister (OS), corneal amyloid deposits were observed in both eyes by slit-lamp biomicroscopy. Indirect ophthalmoscopy revealed vitreous opacities, pale optic discs and atrophy in the peripheral retina in both eyes (figure 1).

Cross sectional SS-OCT images showed a shallow foveal depression and a thinning of the inner retinal layer especially temporal to the fovea. An ellipsoid zone could not be detected, and irregularities of the retinal pigment epithelium (RPE) at the temporal area was observed in the both eyes. A hyporeflective band was detected just below the RPE in both eyes even though the structures of the deep choroidal layer below the hyporeflective band were clearly visible in the SS-OCT images (figure 2). The central retinal thickness was $172 \mu \mathrm{m}$ OD and $208 \mu \mathrm{m}$ OS. The thickness of the subfoveal choroidal and subfoveal hyporeflective bands were $264 \mu \mathrm{m}$ and $95 \mu \mathrm{m}$ OD and $250 \mu \mathrm{m}$ and $97 \mu \mathrm{m}$ OS, respectively.

The superficial and deep capillary plexuses of the retinal vessels were visible in the OCTA images although the density of the capillaries was reduced in both images (figure 3). The retinal vessels were also projected onto the choroid capillary slab as projection artefacts. No signal information at the segmentation ranges of the full-thickness of the hyporeflective band including the choriocapillaris was observed after removing the projection artefacts (figure 4).

\section{OUTCOME AND FOLLOW-UP}

No change within a year.

\section{DISCUSSION}

The OCTA images of the eyes of our patient with severe systemic amyloydosis due to CAPS showed not only a reduction of the retinal capillary density at the inner retinal layer but also the loss of choriocapillaris blood flow at the hyporeflective choriocapillaris band in the cross sectional OCT. Roybal et $a l^{6}$ conducted a retrospective analysis of four patients with amyloidosis-induced chorioretinopathy, and they reported a thicker hyporeflective choriocapillaris band in the OCT images. This band 


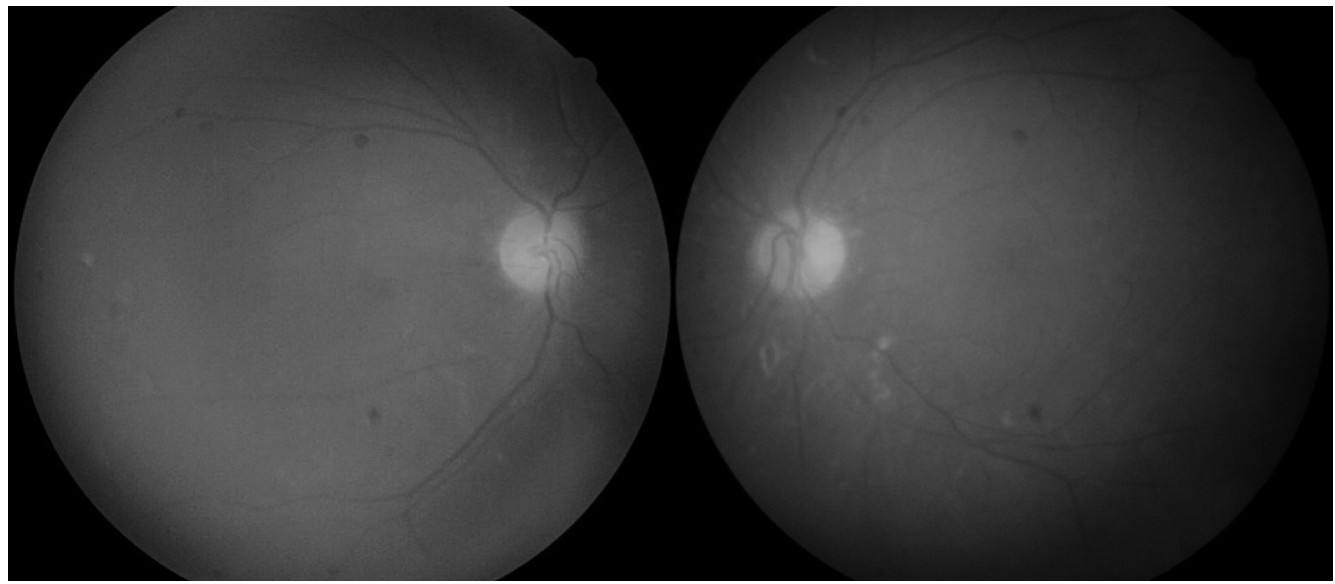

Figure 1 Fundus photographs showing the blurred images due to the vitreous opacities and the pale optic discs in both eyes.

is similar to the hyporeflective band in the SS-OCT images in our case. They stated that the appearance of this band was caused by the accumulation of amyloid and the choriocapillaris appeared to be occluded. They also stated that the outer nuclear layer was thinner which could have been due to a reduction of the choroidal circulation. Some of their cases also had a thinning of the inner retina, and they might have included these cases with the retinal capillary abnormalities. However, this can not be proven because they did not have OCTA data.

Amyloid deposits in the choroid, especially in the choriocapillaris, were reported in a histopathological study by Ts'o and Bettman. ${ }^{7}$ They documented the occlusion of the choriocapillaris by amyloid deposits in a patient with primary systemic amyloidosis. They also stated that there were no abnormal retinal capillaries and no amyloid deposits in the entire inner retinal layer. On the other hand, Yamashita et $a l^{8}$ reported the presence of amyloid deposits in the inner retinal layer, and these were connected to the vitreous. Other studies reported amyloid deposits extending from the retina to the vitreous body, and these investigators raised some concern on the effects of the amyloid deposits on the inner retinal layer. ${ }^{9} 10$ Our case had not only severe amyloidosis, but was also undergoing haemodialysis which could have affected the retinal and choroidal capillaries. Even so, amyloid deposition may occur in both retinal and choroidal capillaries if it is in quite severe cases.

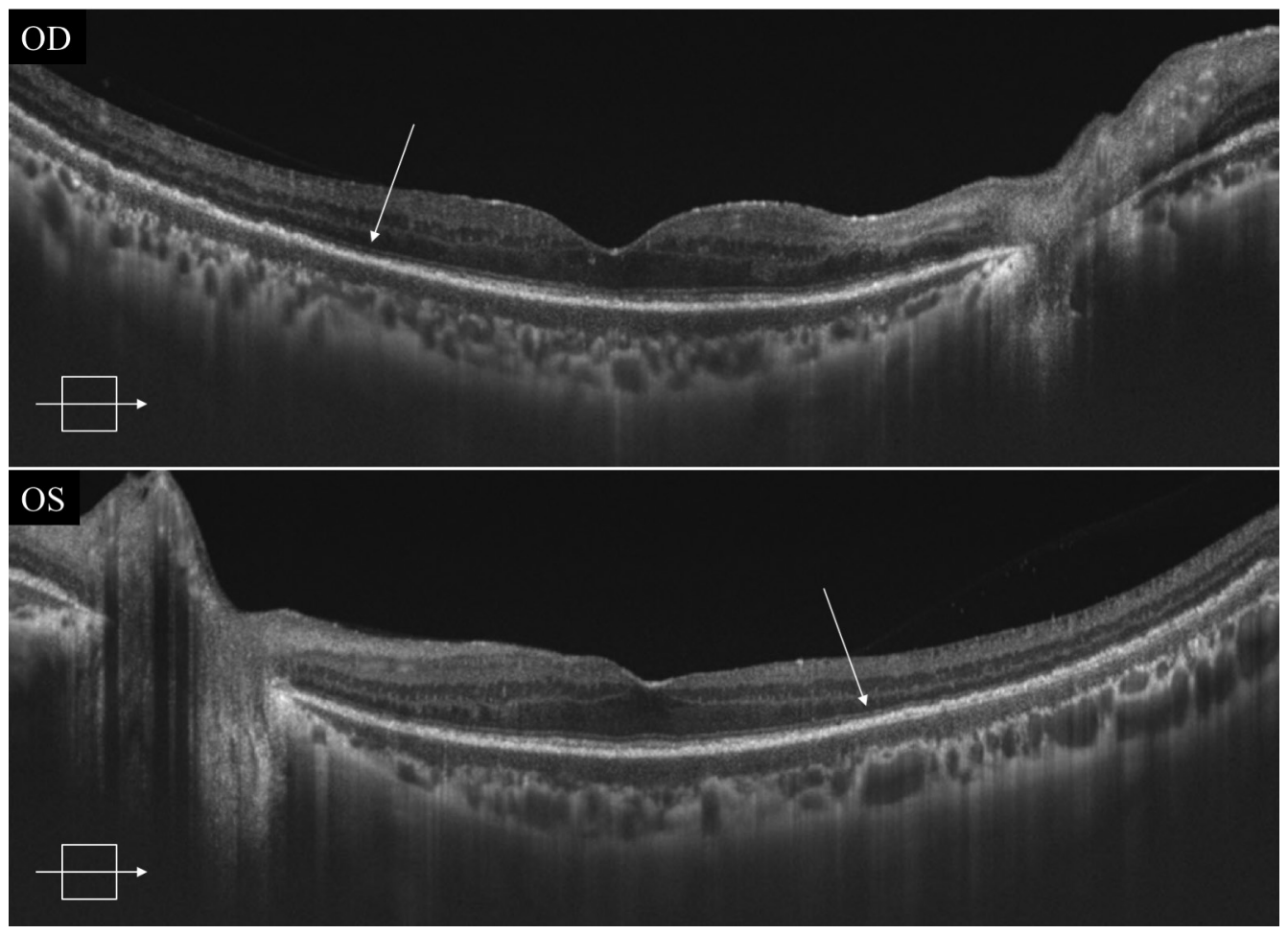

Figure 2 Swept source optical coherence tomographic image showing an absence of the ellipsoid zone on the temporal side of the retina (arrows), and the presence of a hyporeflective band just below the retinal pigment epithelium in both eyes. The thickness of the hyporeflective band at the subfovea is $95 \mu \mathrm{m}$ OD and $97 \mu \mathrm{m}$ OS. 


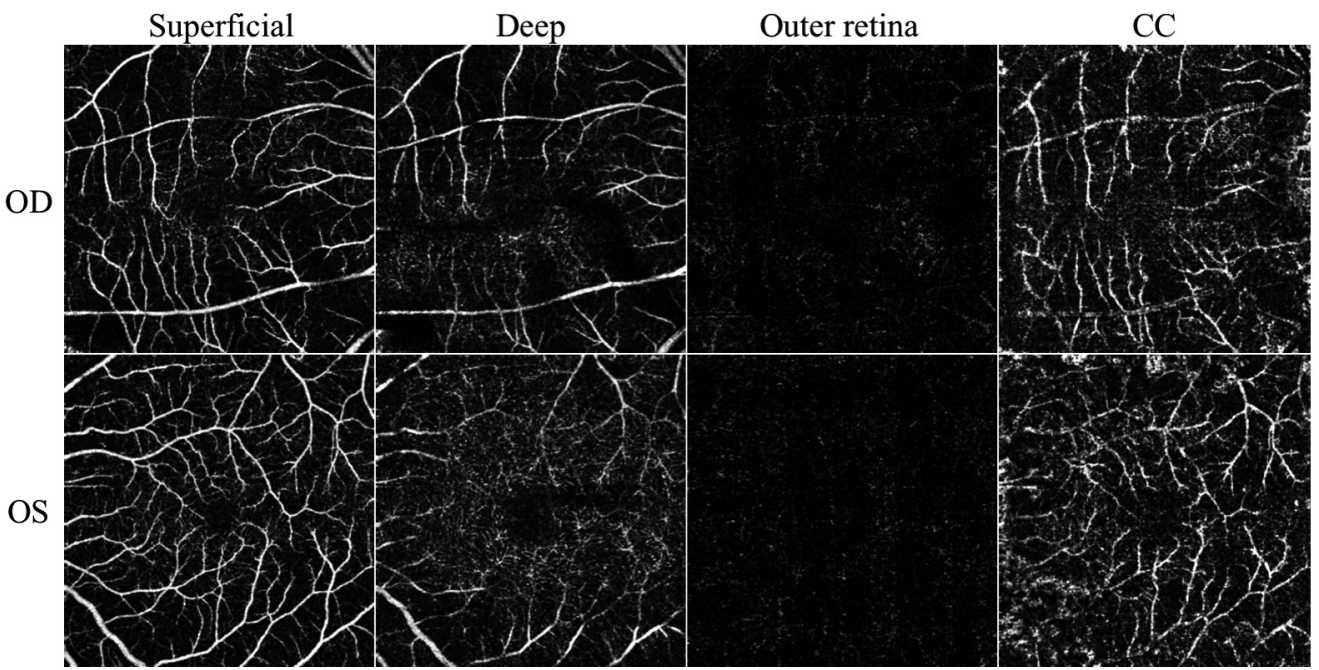

Figure 3 Optical coherence tomography angiography $(6 \times 6 \mathrm{~mm})$ shows the decrease in the density of the retinal capillaries in both the superficial and deep capillary plexuses, and the obvious retinal vessels projected at the choroid capillary slab. CC, choroid capillary.

To our best knowledge, this is the first report of a signal loss of not only the retinal capillaries but also the choriocapillaris in a patient with severe systemic amyloidosis as determined by OCTA. Although amyloid deposits have been confirmed pathologically in the retina and choroid, our findings were obtained noninvasively and in situ by OCTA. Our findings indicate that it is important to evaluate the circulation of choriocapillaris as its occlusion can cause the atrophy of outer retina and dysfunction of RPE. Because the deeper choroidal structures were clearly visible in the cross-sectional SS-OCT images, the full-thickness

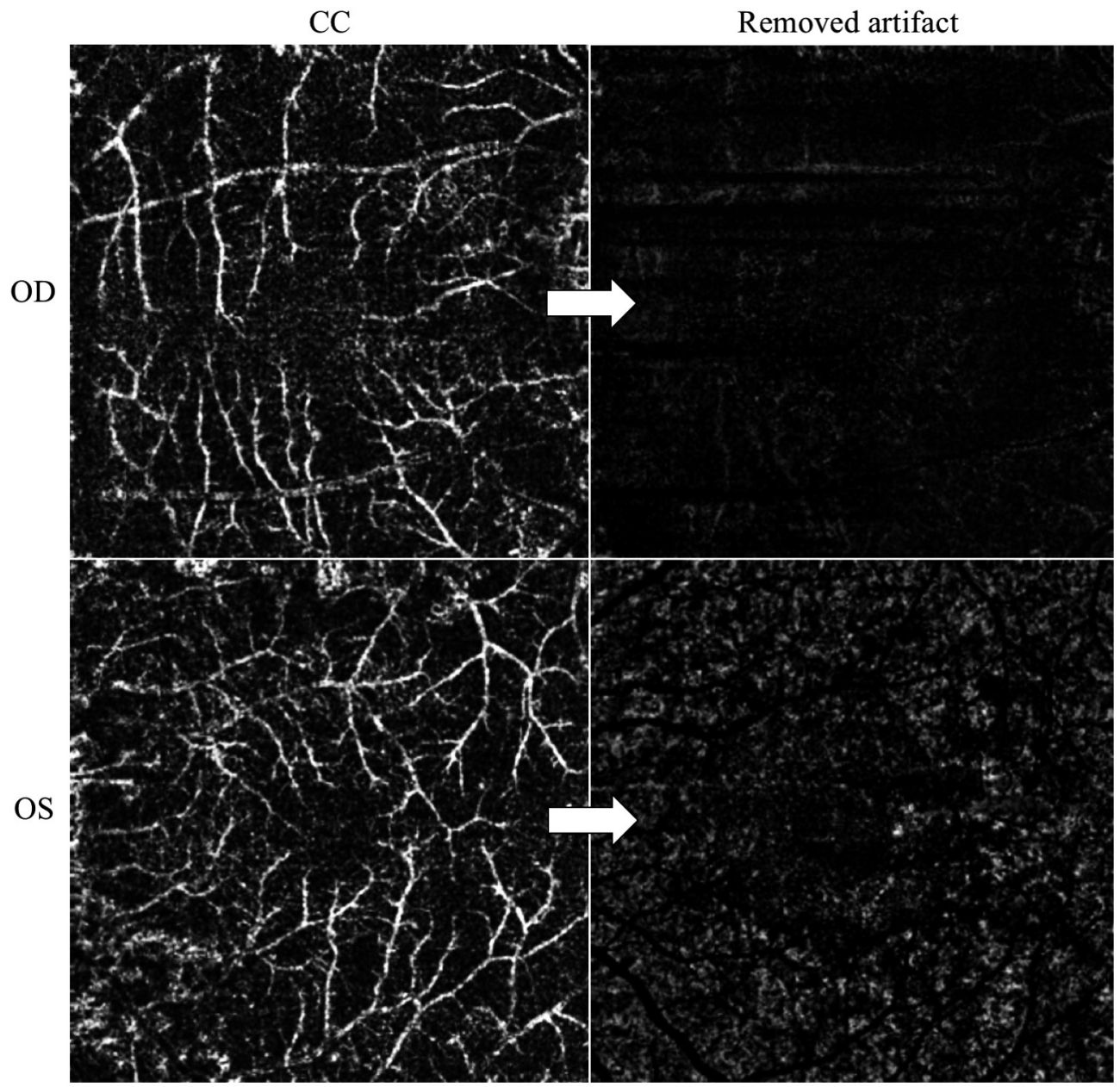

Figure 4 Optical coherence tomography angiography $(6 \times 6 \mathrm{~mm})$ shows an absence of blood flow signals in the choroid capillary slab after removing the projection artefacts. CC, choroid capillary. 
hyporeflective band might be caused by the occlusion of the choriocapillaris. The findings in this patient demonstrate the usefulness of OCTA in monitoring the chorioretinal condition in patients with amyloidosis-induced chorioretinopathy.

\section{Learning points}

- Amyloid deposits with multiple organs including the eye, and is sometimes associated with chorioretinopathy.

- Optical coherence tomography shows the thick hyporeflective choriocapillaris band.

- Optical coherence tomography angiography shows not only a reduction of the retinal capillary but also the loss of choriocapillaris blood flow.

Contributors Designing and conducting of study: MT, IM. Data collection: MT, IM, EU. Analysis and interpretation of data: MT, IM, EU. Manuscript preparation and review: MT, IM, EU, TI. Approval of the manuscript: MT, IM, EU, TI.

Funding The authors have not declared a specific grant for this research from any funding agency in the public, commercial or not-for-profit sectors.

Competing interests None declared.

Patient consent for publication Obtained.

Open access This is an open access article distributed in accordance with the Creative Commons Attribution Non Commercial (CC BY-NC 4.0) license, which permits others to distribute, remix, adapt, build upon this work non-commercially, and license their derivative works on different terms, provided the original work is properly cited and the use is non-commercial. See: http://creativecommons.org/ licenses/by-nc/4.0/

\section{REFERENCES}

1 Cuisset L, Jeru I, Dumont B, et al. Mutations in the autoinflammatory cryopyrinassociated periodic syndrome gene: epidemiological study and lessons from eight years of genetic analysis in France. Ann Rheum Dis 2011;70:495-9.

2 Pece A, Yannuzzi L, Sannace C, et al. Chorioretinal involvement in primary systemic nonfamilial amyloidosis. Am J Ophthalmol 2000;130:250-3.

3 Scuderi G, Abdolrahimzadeh S, Troccola A, et al. Surgical treatment of a rare case of bilateral ptosis due to localised ocular amyloidosis. Saudi J Ophthalmol 2016;30:201-3.

4 Ando T, Oshitari T, Saito M, et al. A case of conjunctival amyloidosis with repeated subconjunctival haemorrhage. Case Rep Ophthalmol Med 2017;2017:1-5.

5 Venkatesh P, Selvan H, Singh SB, et al. Vitreous amyloidosis: Ocular, systemic, and genetic insights. Ophthalmology 2017;124:1014-22.

6. Roybal CN, Sanfilippo CJ, Nazari H, et al. Multimodal imaging of the retina and choroid in systemic amyloidosis. Retin Cases Brief Rep 2015;9:339-46.

7 Ts'o MO, Bettman JW. Occlusion of choriocapillaris in primary nonfamilial amyloidosis. Arch Ophthalmol 1971;86:281-6.

8 Yamashita $\mathrm{H}$, Ishi Y, Ando K, et al. Systemic amyloidosis: Histochemical observation of the eye. J Clin Electron Microscopy 1990;23:183-93.

9 Inomata H, Okayama M, Oshima K. Familial primary amyloidosis: Light and electron microscopic histopathology of the eye. Jpn J Ophthalmol 1976;20:51-62.

10 Hattori T, Shimada H, Yuzawa M, et al. Needle-shaped deposits on retinal surface in a case of ocular amyloidosis. Eur J Ophthalmol 2008;18:473-5.

Copyright 2019 BMJ Publishing Group. All rights reserved. For permission to reuse any of this content visit https://www.bmj.com/company/products-services/rights-and-licensing/permissions/

BMJ Case Report Fellows may re-use this article for personal use and teaching without any further permission.

Become a Fellow of BMJ Case Reports today and you can:

- Submit as many cases as you like

- Enjoy fast sympathetic peer review and rapid publication of accepted articles

- Access all the published articles

- Re-use any of the published material for personal use and teaching without further permission

For information on Institutional Fellowships contact consortiasales@bmjgroup.com

Visit casereports.bmj.com for more articles like this and to become a Fellow 